\title{
Application of Electron Beam Welding Technique for Joining Ultrafine-Grained Aluminum Plates
}

\author{
MARTA ORŁOWSKA, FLORIAN PIXNER, KAMIL MAJCHROWICZ, \\ NORBERT ENZINGER, LECH OLEJNIK, and MALGORZATA LEWANDOWSKA
}

\begin{abstract}
The present study is the first attempt to join ultrafine-grained materials by electron beam welding. The aim of the study was to check the feasibility and effectiveness of this type of welding for thermally unstable materials. The results obtained are of high interest, while the welding did cause a decline in mechanical properties, the results were comparable to those obtained using solid-state welding, but with a significant advantage of narrower fusion- and heat-affected zones.
\end{abstract}

https://doi.org/10.1007/s11661-021-06509-w

(C) The Author(s) 2021

ELECTRON beam welding $(\mathrm{EBW})^{[1]}$ is a modern welding technique in which materials are welded by melting due to being impacted with high-energy electrons. During fusion welding, there is a liquid flow, solidification, and thermal cycle which have a significant impact on the microstructure and mechanical properties in the fusion zone (FZ). This zone is characterized by columnar and equiaxial dendrites. In addition, there may be an equiaxial grains zone followed by a heat-affected zone (HAZ). Due to the concentrated heat input in EBW, the resulting HAZ is very narrow, and extensive grain coarsening does not occur. This technique is also characterized by a large ratio of weld depth to width, negligible deformation of the workpiece, and very high efficiency.

Due to the numerous advantages and possibilities of EBW, in this work an attempt was made to weld materials having an ultrafine-grained $(\mathrm{UFG})^{[2]}$ structure. Such materials possess enhanced mechanical properties compared to their coarse-grained (CG) counterparts because they have a greater number of structural defects such as grain boundaries and dislocations. In the case of commercially pure aluminum, processing by up to 16

MARTA ORŁOWSKA is with the Faculty of Mechanical Engineering, Military University of Technology, Kaliskiego 2, 00-908 Warsaw, Poland. Contact e-mail: marta.orlowska@wat.edu.pl FLORIAN PIXNER and NORBERT ENZINGER are with the Institute of Materials Science, Joining and Forming, Graz University of Technology, Kopernikusgasse 24/I, $8010 \mathrm{Graz}$, Austria. KAMIL MAJCHROWICZ and MAŁGORZATA LEWANDOWSKA is with the Faculty of Materials Science and Engineering, Warsaw University of Technology, WoŁoska 141, 02-507 Warsaw, Poland. LECH OLEJNIK is with the Faculty of Production Engineering, Warsaw University of Technology, Narbutta 85, 02-524 Warsaw, Poland. Manuscript submitted 26 July 2021; accepted 20 October 2021.

Article published online November 10, 2021 passes of equal channel angular pressing (ECAP) resulted in an improvement in yield strength by a factor of about 4, from 48 to $192 \mathrm{MPa} \cdot{ }^{[3]}$ Numerous papers show a significant increase in mechanical strength, e.g., a doubled increase in tensile stress after 8 passes of ECAP of Al-Cu alloy, from $200 \mathrm{MPa}$ to more than $400 \mathrm{MPa}{ }^{[4]}$ Nevertheless, UFG materials have limited thermal stability and are susceptible to grain coarsening due to heat exposure. Therefore, welding with established techniques (e.g., gas tungsten arc welding (GTAW)) causes a significant decrease in their mechanical properties due to grain growth, as was shown for e.g., UFG stainless steel. ${ }^{[5]}$ Additionally, the size of the HAZ is difficult to limit, hence, the idea of using EBW for such thermally unstable materials.

The aim of this study is to investigate the feasibility and effectiveness of EBW on UFG materials. The microstructure and mechanical properties are compared with the results obtained for a CG material. To the best of the authors' knowledge, this work is the very first attempt to apply EBW to a UFG material.

Commercially pure aluminum AA1050 (min. $99.50 \mathrm{wt}$ pct of $\mathrm{Al}$ ) was selected as the test material. It was examined in two states: CG (annealed) and UFG after severe plastic deformation. In the latter case, incremental ECAP (I-ECAP) ${ }^{[6]}$ was chosen as the deformation technique. Eight passes with route $\mathrm{C}$ were conducted at room temperature, giving an equivalent strain of 9.2. The samples, in the form of rectangular plates with a thickness of $3 \mathrm{~mm}$, were subjected to welding.

The welding experiments were performed using an EBW device, a Pro-beam EBG 45-150 K14. The pressure in the working chamber was below $5 \times 10^{-3}$ mbar. The beam axis of the EBW device was vertical, and all the welds were conducted in the flat position $(1 \mathrm{~F} /$ PA). The welding parameters were selected based on a 
preliminary study, and resulted in a complete weld penetration, and a sound visual appearance and root formation. In addition, the parameters were selected so as to minimize the power/energy input in order to reduce the temperature/heat exposure time, while still achieving complete weld penetration and avoiding weld imperfections (e.g., undercut). The process-relevant input parameters were fixed for all experiments and are listed in Table I.

Macrographs of the welds are shown in Figure 1. Good quality welds were obtained without the presence of macroscopic imperfections such as cracks or porosity. Both welds are characteristic of the EBW technique with a narrow FZ in the center. Distinct differences between the welds are visible. For the weld of $\mathrm{CG} \mathrm{Al,} \mathrm{the} \mathrm{grain}$ size does not change significantly over the weld's cross-section; only the shape and orientation change. In the case of the weld made of UFG Al, the grain size in the FZ is noticeable larger than in the base material (BM). For both welds, the FZ is characterized by an as-cast structure due to rapid solidification, and consists of a mixed microstructure that includes equiaxed and columnar dendrites.

For a detailed characterization of the microstructure, an analysis was performed on a scanning electron microscope with an electron backscatter diffraction detector. Orientation maps (OIMs), together with maps of the grain boundary distribution, are presented in Figure 2. The maps distinguish the changes in microstructure from the center line through all the zones characteristic for EBW. The dendrites in the FZ have an average size of about $20 \mu \mathrm{m}$ for the $\mathrm{CG}$ weld and $18 \mu \mathrm{m}$ for the UFG weld, while for the BMs the average grain sizes are $15 \mu \mathrm{m}$ and $1 \mu \mathrm{m}$, respectively. In the FZ, the variety of the dendrites size is significantfrom a few microns to above $200 \mu \mathrm{m}$. In the transition zone in both welds, the grains are elongated in the direction of the solidification. However, in the $\mathrm{CG} \mathrm{Al}$ weld, the columnar grains are thicker, up to $150 \mu \mathrm{m}$ wide, while for the UFG Al weld their average size is reduced and their width does not exceed $70 \mu \mathrm{m}$. This is caused by the epitaxial growth of the columnar dendrites. Their width corresponds to the diameter of the equiaxed grains in the coarse-grained HAZ; extensive grain coarsening in the HAZ is suppressed by the rapid welding speeds characteristic of EBW. As the grain size in the HAZ decreases, the size of the dendrites also

Table I. Summary of Relevant Parameters of EBW

\begin{tabular}{llll}
\hline Attribute & & Unit & Values \\
\hline Acceleration Voltage & $U_{\text {acc }}$ & $\mathrm{kV}$ & 80 \\
Beam Current & $I_{\text {beam }}$ & $\mathrm{mA}$ & 24 \\
Welding Speed & $v_{\text {weld }}$ & $\mathrm{mm} / \mathrm{s}$ & 25 \\
Input Power & $P$ & $\mathrm{~W}$ & 1920 \\
Input Energy & $E$ & $\mathrm{~J} / \mathrm{mm}$ & 76.8 \\
Focal Position & $f_{\mathrm{p}}$ & - & Surface \\
Beam Figure & - & - & Circle \\
Oscillation Frequency & $f$ & $\mathrm{~Hz}$ & 1000 \\
Amplitude of Deflection & $x, y$ & $\mathrm{~mm}$ & $\varnothing 0.5$ \\
Working Distance & - & $\mathrm{mm}$ & 800 \\
\hline
\end{tabular}

decreases. This suggests that the microstructure of the BM influences the microstructure of the FZ. Therefore, for the $\mathrm{CG} \mathrm{Al}$ weld there is a smooth transition from the FZ to the BM and the changes in grain boundary density are not significant. The smallest grains are observed in the center line of the weld, and this can be attributed to the change in the solidification direction, since we are observing the grain shape in one plane only.

In the case of the UFG Al weld, coarse grains with a size of several microns can be observed after the columnar grain zone. Their size is significantly smaller than in the CG Al weld. A detailed map of the transition zone of the UFG Al weld is shown in Figure 3, where a gradual change in grain size can be observed. As the BM is approached, the grain boundary density and the fraction of LAGB increase. In the FZ and HAZ, the vast majority of grain boundaries are HAGBs. In the FZ, the fraction of HAGBs is estimated as being 78 pct, in the HAZ near the columnar grains this value increases to 84 pct, and then gradually decreases closer to the BM. For the BM UFG Al this value equals 56 pet. The HAZ of the UFG Al weld is approximately $1 \mathrm{~mm}$.

Also, the microtexture changes across the weld cross-sections, which can be seen at $\{111\}$ the pole figures (see Figure 2 top). For the CG BM, a texture typical for recrystallized fcc metals can be observed, with the cube texture $\{100\}<001>^{[7]}$ as the main component. In the FZ, a random texture can be observed, without any dominant components. In the case of the UFG BM, the initial material has a shear texture, as the I-ECAP introduces a shearing texture with $\mathrm{A}\{111\}<110>$ and $\mathrm{C}\{001\}<110>^{[8]}$ as dominant components. In the FZ, the texture components are similar to the $\mathrm{CG} A \mathrm{Al}$ weld, with none dominating.

The investigation of mechanical properties included microhardness measurements and static tensile tests. Microhardness maps of the weld cross-sections are presented in Figure 4. Both welds reveal a symmetrical microhardness distribution, with distinct differences between the welds in relation to the BM. For the $\mathrm{CG} \mathrm{Al}$ weld, the microhardness distribution does not change significantly. Therefore, it is difficult to distinguish different zones in the weld. The average microhardness of the BM is $27 \mathrm{HV0.1}$, while that of the FZ is 29 HV0.1. This indicates a moderate increase due to the presence of an area of smaller grains in the center of the weld (Figure 2). There is no distinct HAZ in this weld. The opposite situation is observed for the second weld. I-ECAP led to an increase in microhardness of up to 54 HV0.1. In the FZ, the microhardness dropped significantly to an average value of $31 \mathrm{HV} 0.1$, which is higher than for the CG Al weld. This is in an agreement with the smaller average grain size in this zone for the UFG Al weld. Outside the FZ, an HAZ can be distinguished, where the microhardness varies from $30 \mathrm{HV} 0.1$ up to the same value as that of the BM. The size of this zone is about 1-1.5 mm wide, which is well correlated with the observations of the microstructure (see Figure 3).

The representative stress-strain curves from the tensile tests are presented in Figure 5. The results are shown for both welds, but also for the BMs. The CG sample 


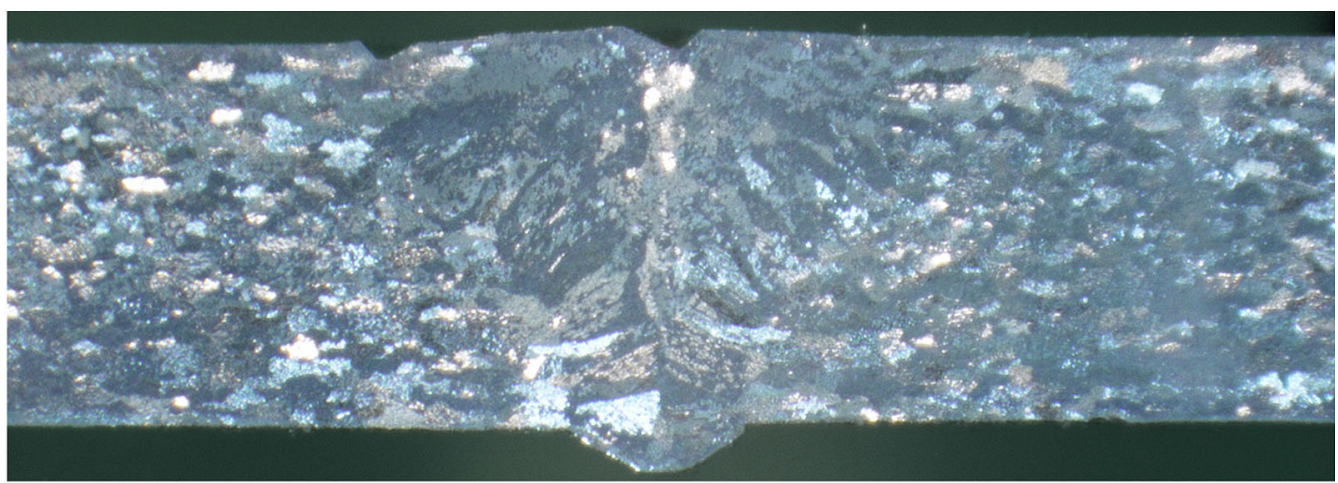

(a)

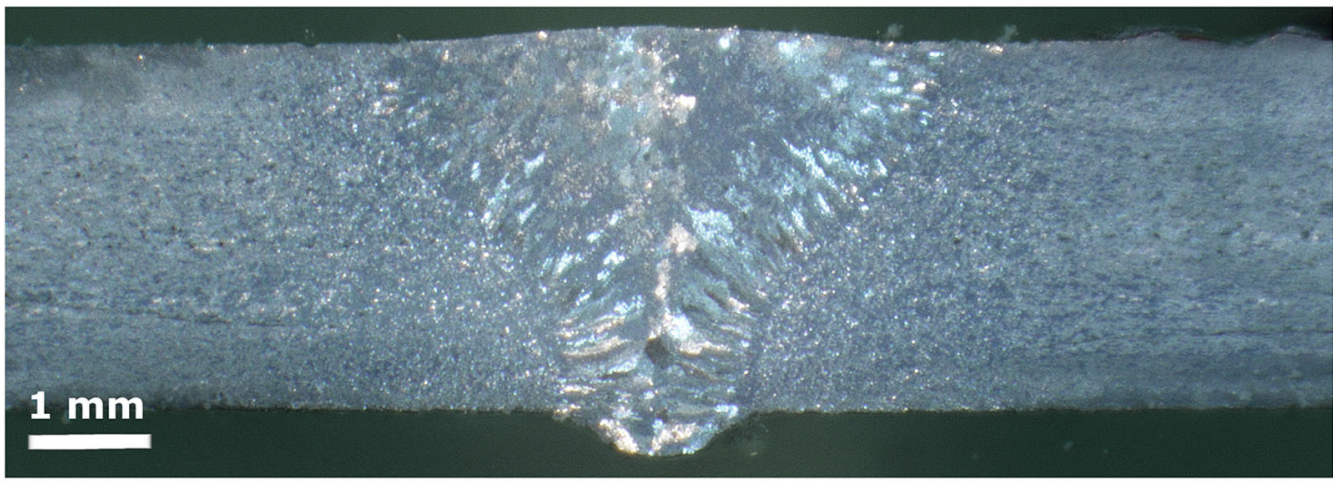

(b)

Fig. 1-Macrographs of the (a) $\mathrm{CG} \mathrm{Al}$ and (b) UFG Al EB welds.

has a low UTS value of about $64 \pm 1 \mathrm{MPa}$, and the elongation to break equals $48 \pm 1$ pct. The processing of I-ECAP led to a significant improvement in UTS, which increased to $178 \pm 1 \mathrm{MPa}$, although the elongation to break decreased to $15 \pm 1$ pct. These results and changes are typical for CG and UFG materials, and are consistent with the changes in grain size and the Hall-Petch equation. The strain location was in the $\mathrm{BM}$ in the CG $\mathrm{Al}$ weld, but in the FZ in the UFG $\mathrm{Al}$ weld. This indicates that the rupture occurred in the areas with the biggest grain size. As a result, the stress-strain curve for the $\mathrm{CG} \mathrm{Al}$ weld follows the curve for the BM. In the UFG Al weld, the UTS is reduced compared to the UFG base material, with an average value of $87 \pm 2 \mathrm{MPa}$, whereas the elongation to break went up to $22 \pm 5$ pct. The results obtained in these tests for the CG Al weld are exceptional, showing a weld efficiency of 100 pct, and for the UFG Al weld 50 pct.

Since there have been no studies on welding UFG materials using the EBW technique, the results obtained can only be compared with those from CG materials. The literature data show that changes in the microhardness of the weld cross-sections for aluminum and its alloys depend on the strengthening mechanism of the BM. For precipitate-hardened alloys, e.g., 2xxx and $6 \mathrm{xxx}$, the decrease in hardness in the FZ was significant, and is estimated as being over 50 pct, while for a work-hardened 5xxx Al alloy the decrease was much milder, at about 20 to 25 pct. ${ }^{[9]}$ In these cases, the joint efficiency in terms of UTS was about 71,80 , and 80 pct, for the 2xxx, 6xxx, and 5xxx, respectively. Excessive temperature and the prevailing vacuum during EBW can lead to intensive evaporation of alloying elements, as in the case of AA2195 aluminum-lithium alloy, ${ }^{[10]}$ where the evaporation of the latter element caused changes in strengthening from precipitates, resulting in a joint efficiency of about 60 pct. However, in the case of pure aluminum, this problem is not present. Therefore, in this study an efficiency of 100 pet for UTS was achieved for the CG Al weld. Moreover, there was even a moderate increase in microhardness in the FZ. For the UFG Al weld, the efficiency in terms of UTS was 50 pct, and in terms of microhardness was 56 pct, which is lower than the value presented in the above literature data. However, when EBW is compared with other joining techniques used for UFG Al, the results are much more promising.

In the case of UFG aluminum and its alloys, solid-state welding techniques such as friction stir welding (FSW) are mainly used. ${ }^{[11]}$ Our previous works investigated the effectiveness of FSW for UFG Al. ${ }^{[12,13]}$ In both studies, due to the continuous dynamic recrystallization in the stir zone (SZ), the average grain size increased from about $1 \mu \mathrm{m}$ to 3-6 $\mu \mathrm{m}$, which caused a decrease in microhardness to about 30-32 HV0.2, which is similar to the results of this study, despite the much larger grain size in the FZ. The reason for this may lie in certain processes that take place during EBW. Vaporization may occur, but, contrary to $\mathrm{Al}$ alloys, it has a beneficial effect. It allows impurities that adversely affect 


\section{CG Al}

BM
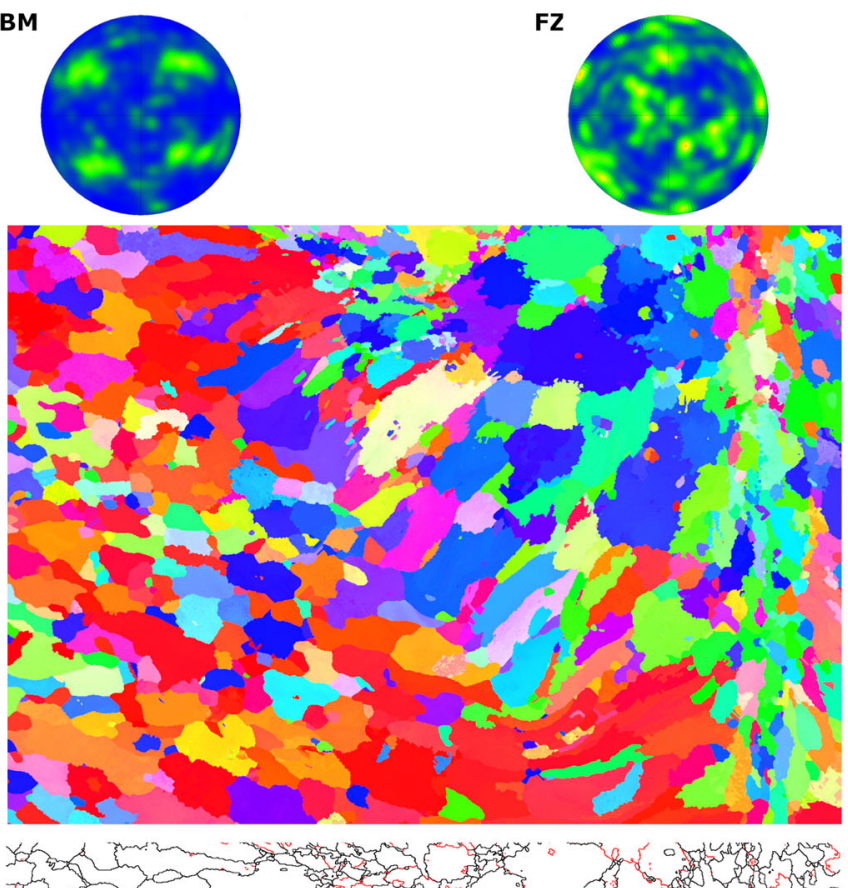

FZ

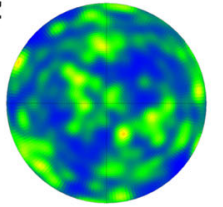

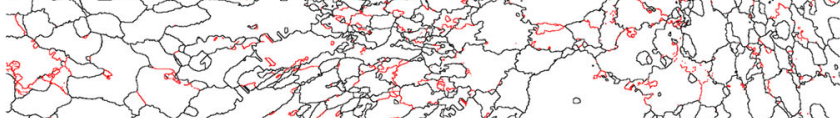
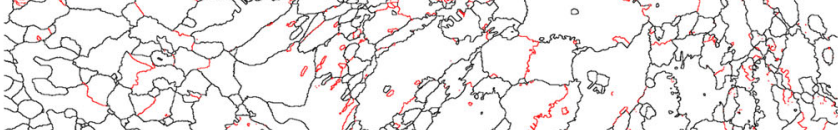

Fo vo 3 ल

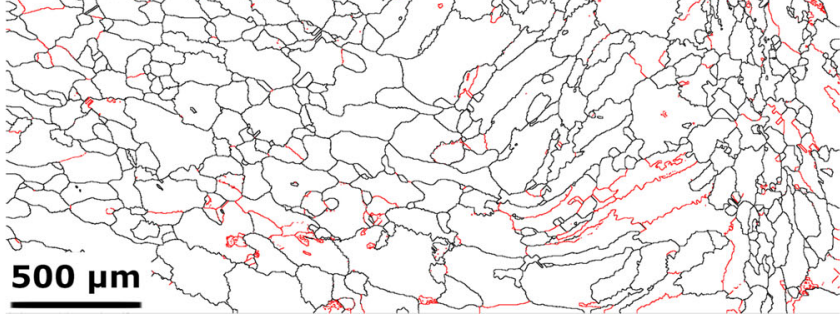

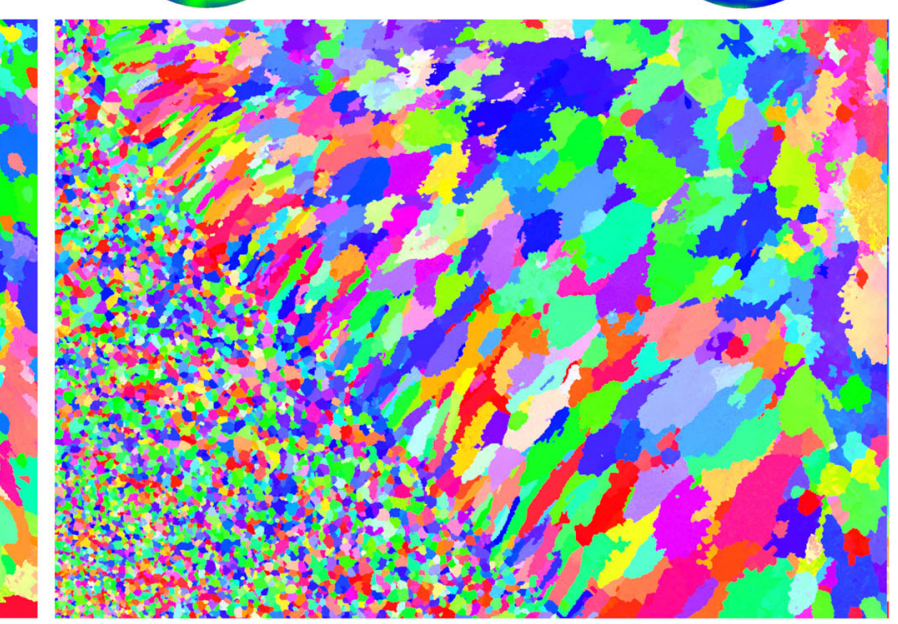
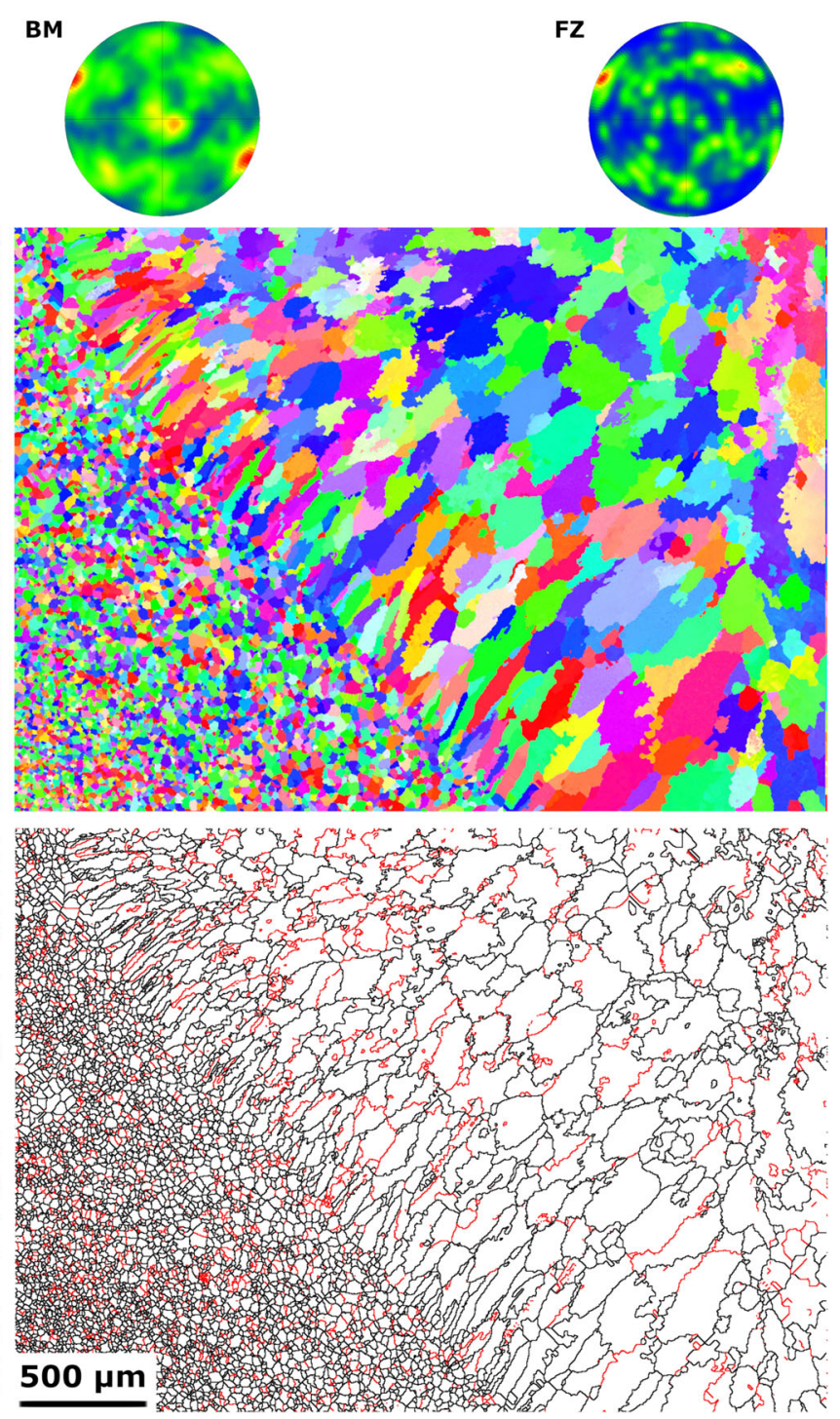

Fig. 2-OIMs together with $\{111\}$ pole figures from the BM and the FZ; distribution of grain boundary maps of welds from CG and UFG AA 1050 (red denotes LAGBs, black-HAGBs) (Color figure online).

the mechanical properties to evaporate. Also, the residual stresses in the FZ can lead to a moderate improvement in the mechanical properties as a result of solidification and subsequent rapid cooling.

In other works describing welding using FSW, there was a decrease in microhardness in the SZ similar to the results obtained in the present study. For example, for AA1050 after accumulative roll bonding (ARB), the microhardness went down from $50 \mathrm{HV}$ to $31-40 \mathrm{HV}$, depending on the process parameters ${ }^{[14]}$ or from 50 HV0.05 to 38 HV0.05 in Reference 15. For AA1050 after 2 passes of constrained groove pressing, the microhardness in the SZ decreased to $27 \mathrm{HV} \cdot{ }^{[16]}$ It can therefore be concluded that, in the weld area of the UFG material, the microhardness decreases, since it is not possible to preserve an ultrafine-grained size regime in commercially pure aluminum, regardless of whether the welding is performed in the solid or liquid state. In

UFG Al 

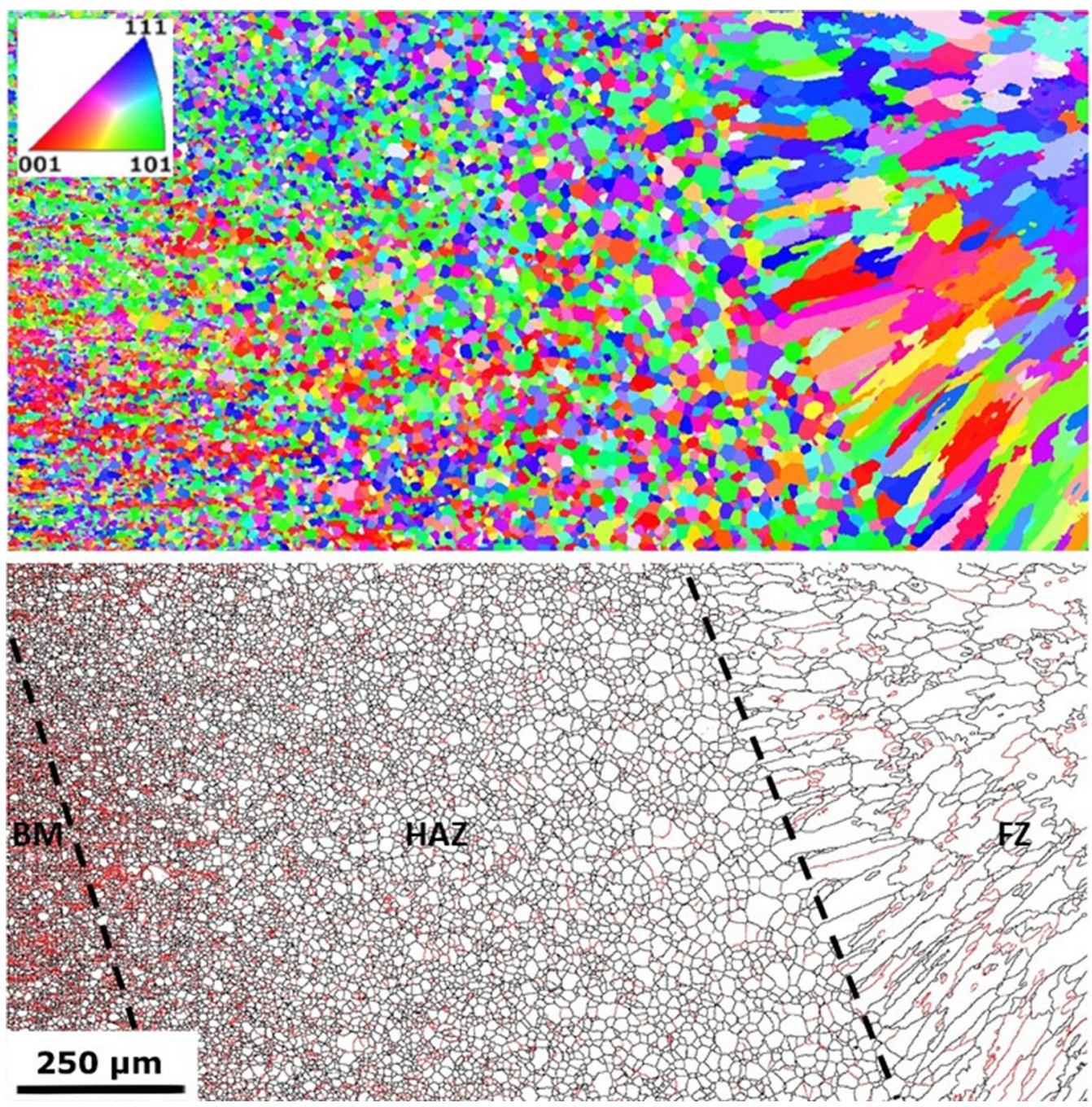

Fig. 3-OIMs (top) and grain boundary distribution map (bottom) for the UFG Al weld.

material results in smaller-sized grains in the HAZ and FZ. For EBW, the refined microstructure is beneficial and makes it possible to achieve better results in the weld zones, i.e., to obtain better mechanical properties. In the FSW process, the initial microstructure does not affect the $\mathrm{SZ},{ }^{[1213]}$ as dynamic recrystallization occurs and the microstructure in the SZ depends only on process parameters. Another advantage of EBW over FSW is texture formation. For the EBW weld, a random texture was obtained in the FZ (Figure 2), while for FSW joints a strong shear texture is observed in the $\mathrm{SZ},{ }^{[17]}$ which can have a detrimental effect on some properties, such as corrosion resistance.

Since the EBW process takes place under a vacuum atmosphere, the prevailing vacuum also prevents contamination of the weld by impurities or interstitial elements from the environment, and also evaporates surface oxides and residual impurities in the material during the process. Porosity in conventionally fusionwelded aluminum (e.g., GTAW) is often the result of hydrogen gas becoming trapped in the solidifying aluminum weld pool (since it is highly soluble in molten aluminum), resulting in undesirable properties of the final weld. In general, EB welds are characterized by the highest quality compared with other fusion welding techniques. Moreover, EBW exhibits a high potential for further development when used with UFG materials: higher welding speeds can be targeted to further minimize temperature exposure time, further minimize the weld zone, and achieve narrower welds (nail-head type). It is already possible to suppress extensive grain coarsening in the HAZ and reduce the grain size with a welding speed of $25 \mathrm{~mm} / \mathrm{s} \mathrm{(e.g.,} \mathrm{which} \mathrm{is} \mathrm{about} 4$ times faster than in FSW experiments ${ }^{[13]}$ ). No porosity or weld defects were observed in all the cross-sections examined, indicating sound integrity. The EBW process, then, not only makes a highly concentrated energy input possible that results in a narrow weld seam, and also provides remarkably high shielding due to its inherent vacuum.

A UFG microstructure is thermally unstable and cannot be maintained by any welding technique. To date, solid-state welding techniques (i.e., FSW) have been considered to be the most promising, since they are conducted at temperatures below the material's melting point. By mixing a heated, plasticized, and deformed material, a still comparably small grain size can be 
(a)

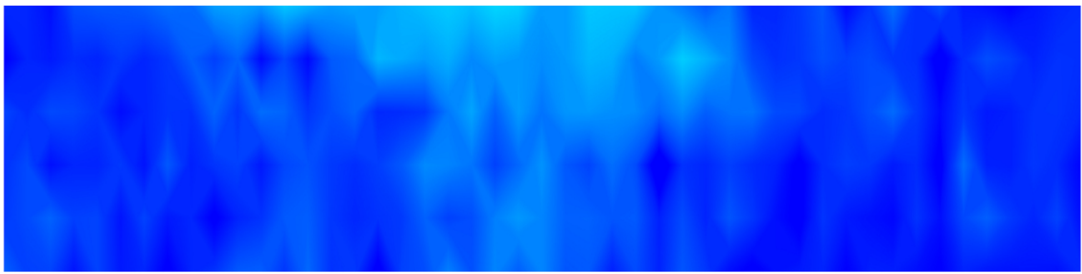

(b)

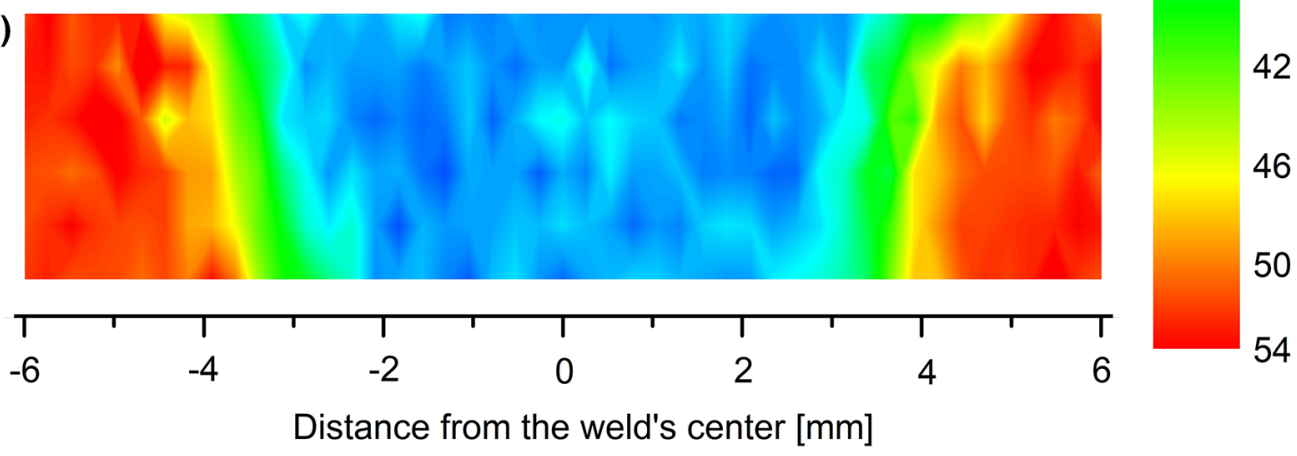

Fig. 4-Microhardness maps of the cross-section of the welds from (a) CG and (b) UFG Al.

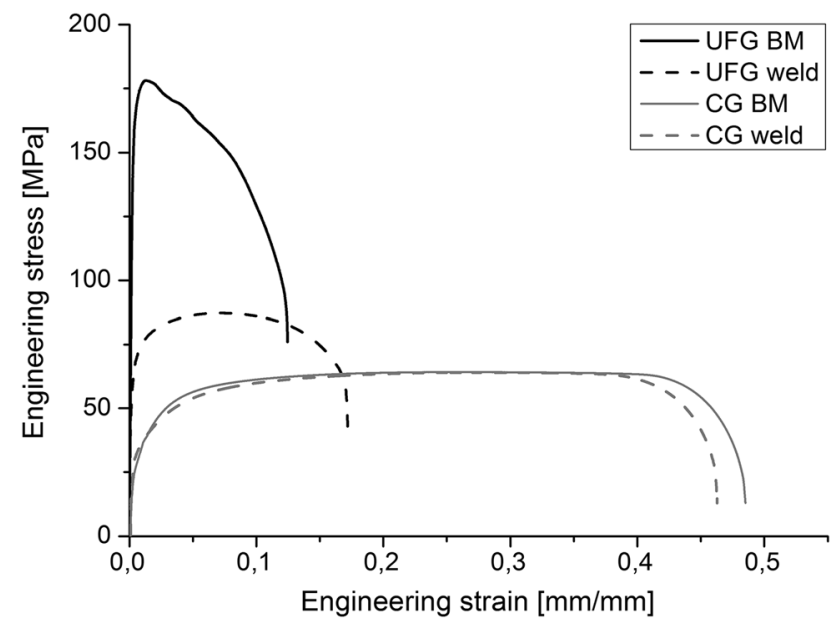

Fig. 5-Representative stress-strain curves for the welds and the BMs.

achieved. However, the weld zone geometry (SZ-TMAZ-HAZ), i.e., the weak zone, is relatively large, since it is defined by the tool geometry (pin, shoulder) as well as by the heat/temperature exposure time. Since the energy input is less concentrated and the welding speeds are comparatively low, the temperature field evolves more broadly in the steady state and the temperature gradient is comparatively low in aluminum due to its thermophysical properties. In addition, since the joint is formed in the solid state, mechanical fixation is also required to prevent severe distortion of the weld. Surface contaminants and oxides can be mixed into the SZ, which then serve as the origin of cracks or delamination during mechanical testing/loading.
This work is the very first attempt to weld UFG materials using the EBW technique. It is a feasibility study, and the results are of great potential. However, at this point the repeatability or standard deviations are unknown. Sound welds were obtained from CG and UFG commercially pure aluminum. Due to solidification in the FZ, there was a decrease in mechanical properties compared with the UFG BM, but an increase in comparison with the CG BM. The results obtained were similar to those achieved using the solid-state welding technique, and the size of dendrites/grains was even significantly higher. Moreover, EBW resulted in an HAZ of about $1 \mathrm{~mm}$, while the width of the area with reduced microhardness did not exceed $9 \mathrm{~mm}$. This shows EBW's great potential for use with UFG materials. Further experiments could lead to further improvements if the heat input is reduced.

On behalf of all the authors, the corresponding author states that there is no conflict of interest.

\section{OPEN ACCESS}

This article is licensed under a Creative Commons Attribution 4.0 International License, which permits use, sharing, adaptation, distribution and reproduction in any medium or format, as long as you give appropriate credit to the original author(s) and the source, provide a link to the Creative Commons licence, and indicate if changes were made. The images or other third party material in this article are included in the article's Creative Commons licence, unless indicated otherwise in a credit line to the material. If material is not included in the article's Creative Commons licence and your intended use is not permitted by statutory 
regulation or exceeds the permitted use, you will need to obtain permission directly from the copyright holder. To view a copy of this licence, visit http://creat ivecommons.org/licenses/by/4.0/.

\section{REFERENCES}

1. M.S. Węglowski, S. Błacha, and A. Philips: Vacuum, 2016, vol. 130, pp. 72-92, https://doi.org/10.1016/j.vacuum.2016.05.004.

2. RZ. Valiev, Y. Estrin, Z. Horita, T.G. Langdon, M.J. Zehetbauer, and Y. Zhu: Jom., 2006, vol. 58, pp. 33-39, https://doi.org/ 10.1007/s11837-016-1820-6.

3. E.A. El-Danaf: Mater. Sci. Eng. A., 2008, vol. 487, pp. 189-200, https://doi.org/10.1016/j.msea.2007.10.013.

4. D.P. Braga, D.C.C. Magalhaes, A.M. Kliauga, C.A. DellaRovere, and V.L. Sordi: Mater. Sci. Eng. A., 2020, vol. 773, p. 138865, https://doi.org/10.1016/j.msea.2019.138865.

5. S. Sabooni, F. Karimzadeh, M.H. Enayati, A.H.W. Ngan, and H. Jabbari: Mater. Charact., 2015, vol. 109, pp. 138-51, https:// doi.org/10.1016/j.matchar.2015.08.009.

6. L. Olejnik, A. Rosochowski, and M. Richert: Mater. Sci. Forum., 2008, vols. 584-586, pp. 108-13.

7. I.L. Dillamore: Acta Metall., 1964, vol. 12, pp. 1005-14.

8. F.C. Liu and T.W. Nelson: Mater. Des., 2017, vol. 115, pp. 467-78, https://doi.org/10.1016/j.matdes.2016.11.066.
9. G. Çam, V. Ventzke, J.F. Dos Santos, M. Koçak, G. Jennequin, V. Ventzke et al:: Sci. Technol. Weld. Join., 1999, vol. 4, pp. 317-23, https://doi.org/10.1179/136217199101537941.

10. G. Chen, Q. Yin, G. Zhang, and B. Zhang: J. Manuf. Process., 2020, vol. 50, pp. 216-23, https://doi.org/10.1016/ j.jmapro.2019.12.052

11. R.S. Mishra and Z.Y. Ma: Mater. Sci. Eng. R Rep., 2005, vol. 50, pp. 1-78, https://doi.org/10.1016/j.mser.2005.07.001.

12. M. Lipińska, L. Olejnik, A. Pietras, A. Rosochowski, P. Bazarnik, J. Goliński et al.: Mater. Des., 2015, https://doi.org/10.1016/ j.matdes.2015.08.129.

13. M. Orlowska, T. Brynk, A. Huetter, J. Goliński, N. Enzinger, L. Olejnik et al.: Mater. Sci. Eng. A., 2020, https://doi.org/ 10.1016/j.msea.2020.139076.

14. Y. Sun, H. Fujii, Y. Takada, N. Tsuji, K. Nakata, and K. Nogi: Mater. Sci. Eng. A., 2009, vol. 527, pp. 317-21, https://doi.org/ 10.1016/j.msea.2009.07.071

15. I. Topic, H.W. Hoppel, and M. Goken: Mater. Sci. Eng. A., 2009, vol. 503, pp. 163-66, https://doi.org/10.1016/j.msea.2007.12.057.

16. M.S. Khorrami, M. Kazeminezhad, and A.H. Kokabi: Mater. Des., 2012, vol. 40, pp. 364-72, https://doi.org/10.1016/ j.matdes.2012.04.016.

17. R.W. Fonda and J.F. Bingert: Scr. Mater., 2007, vol. 57, pp. 1052-55, https://doi.org/10.1016/j.scriptamat.2007.06.068.

Publisher's Note Springer Nature remains neutral with regard to jurisdictional claims in published maps and institutional affiliations. 